\title{
ARMED CONFLICT CHARACTERISTICS AND ITS EFFECTS ON FIRM EXIT ${ }^{1}$
}

\author{
Adriana Camacho Catherine Rodriguez
}

August, 2012

\begin{abstract}
This paper uses two unique panel data sets to study the causal effect that different characteristics of the armed conflict have over firm exit in Colombia. Using a fixed effects estimation methodology at the plant level and controlling for the possible endogeneity of armed conflict through the use of instrumental variables, we find that the particular armed group that operates in a given region, the level of polarization of the conflict as well as the specific target of the attack impact in a differential manner the probability of firm exit. This poses important implications for policy recommendations and actions in the different regions of the country.
\end{abstract}

Key Words: Conflict, Firm Exit, Armed Group, Polarization, Colombia.

JEL codes: D21, J31, R30

\footnotetext{
${ }^{1}$ Adriana Camacho and Catherine Rodriguez are Associate Professors at the Department of Economics, Universidad de Los Andes, emails: adcamach@uniandes.edu.co and cathrodr@uniandes.edu.co respectively. Research assistance from Román Andrés Zárate is gratefully acknowledged. Adriana Camacho thanks Departamento Administrativo Nacional de Estaditicas (DANE) for providing the Annual Manufacturing Survey Data. Finally, we thank the financial support by UKaid from the Department for International Development. All errors are ours.
} 


\section{Introduction}

The high incidence of armed conflicts around the world has significantly increased the interest of academic research on the possible impact of violence on several outcomes of interest. Most of this research has focused on the direct impact that conflict has on its victims and on the households residing in conflict areas. The questions of interest in these studies include the impact of violence on forced migration, households' consumption and investment patterns, general health of individuals and the levels of education attainment and labor decisions of children exposed to conflict, among others. ${ }^{2}$

However, little attention has been given to the impact that conflict may have on firms' decisions, performance and activities. Among the few studies that have addressed the problem of firm activity and civil conflict we find Barro (1991) and Alesina and Perotti (1996). Using cross-country data, both studies show a negative relationship between political instability and economic growth. Similarly, Gaviria (2002) showed that firms' sales in Latin America grow at a lower rate if entrepreneurs believe crime rates are sufficiently high to interrupt business activities. This cross-country evidence, although suggestive, may suffer from omitted variable bias and reverse causality between poverty and conflict if not adequately controlled for. Hence, recent studies have focused on single country information in order to reduce these estimation problems. For instance, Abadie and Gardeazabal (2003) used information in the Basque country to estimate the impact that terrorist activities have on GDP; Collier and Duponchell (2010) use a cross section of firm data and find negative consequences on employment and earnings in Sierra Leone. For Colombia three studies have analyzed this issue. Pshisva and Suarez (2010) established the negative impact that kidnaps have on firms’ investment decisions in Colombia. Rettberg (2008) conducts a survey to 1113 Colombian firms and find out that over $75 \%$ of them would invest more if the conflict is finalized. Finally, Camacho and Rodriguez (2012)

\footnotetext{
${ }^{2}$ For a review on the subject please refer to Blattman and Miguel (2010).
} 
obtain evidence that suggests that armed conflict increases in a significant manner the probability of firm exit.

This paper enriches the existing literature by estimating the effect that the different characteristics of armed conflict have on exit decisions of manufacturing firms. Specifically, this paper answers three questions of interest. The first one is whether the effect of the attacks depends on the armed group who commits it. Different armed groups have different ideologies, war strategies and normally target different objectives suggesting that its effect on entrepreneurial activities should also differ. The second question is how different levels of polarization of the conflict affect the probability of a firm leaving the market. In this paper, we construct an index in which higher values correspond to municipalities where there are fewer armed actors present. The armed conflict in highly polarized zones may differ from the one in municipalities with several armed groups present and hence firm's decisions may also be dissimilar. The third and final question asks whether attacks targeted towards private property have a greater impact on firm exit decision than attacks targeted to generate fear to the civil population.

The answer to these three questions is important for several reasons. First, the study of the manufacturing sector is relevant for Colombia given that it represents approximately 15\% of its GDP. However it is also relevant for other developing countries experiencing armed conflict given the importance that entrepreneurship and firms' activities have on the economic performance of a country. Moreover, authors such as Iyigun and Rodrik (2006) and Munshi (2007) suggest that low levels of development are in part caused by low levels of entrepreneurship. Understanding how the different characteristics of armed conflict affects economic activity at the firm level could provide governments and NGOs with insights on how to reduce its impact on economic activity according to each regions specific characteristic. 
This paper uses information from two unique panel data sets from Colombia that allow us to directly link firms' activities with the specific characteristics of the armed conflict at the municipality level. ${ }^{3}$ The information on entrepreneurial activities used in the present study comes from the Annual Manufacturing Survey (AMS). This is a census of manufacturing plants with more than 10 employees or an annual production above $50.000^{4}$ dollars measured in 2005 prices for the period 1993-2005. Information on armed conflict is obtained from a yearly data set at the municipal level constructed by CEDE (Centro de Estudios sobre Desarrollo Económico, Universidad de los Andes) which contains the number and type of attacks perpetrated by both guerilla and paramilitary groups in Colombia between 1988 and 2004. Our conflict measure will vary according to our question of interest. This information is further complemented with information on government deterrence measures.

In all of these specifications we include firm fixed effects and take into account the possible endogeneity of our variables of interest, and thus we use instrumental variables technic in which contemporaneous armed conflict is instrumented with lagged government deterrence measures. ${ }^{5}$ As in Camacho and Rodriguez (2012) we find that armed conflict increases the probability of firm exit. More interesting we corroborate the hypothesis that this effect varies according to the specific characteristics of the conflict. Regarding the authors of the attacks we find that while attacks perpetrated by the paramilitary groups do not have any effect on firm exit decisions, attacks made by any of the two guerrilla groups have a positive and significant effect. The same is true, although in a smaller magnitude, for attacks made by common criminals. Finally, attacks whose perpetrator is unknown have an

\footnotetext{
${ }^{3}$ Colombia has 31 states and 1120 municipalities within those states.

${ }^{4}$ Using the average exchange rate in 2005: 2300 pesos per US dollar. This is the exchange rate that will be used throughout the paper.

${ }^{5}$ The intuition for choosing these instruments is closely related with recent research by Angrist and Kugler (2008) and is the same one used by Camacho and Rodriguez (2012). This will be explained in more detail in the paper.
} 
important effect on firm exit. We find that greater levels of polarization increase the probability of firm exit decisions. However, this effect is not linear and after a certain threshold the effect starts to diminish. Finally, we find that attacks targeted to private property increases in a higher proportion the probability of firm exit that attacks targeted to the civil population.

The remainder of the paper is organized as follows. Section 2 includes a review of the papers relating conflict with economic activity in the international literature. Section 3, describes the data used in the paper and includes some descriptive statistics. Section 4 explains the empirical strategy, Section 5 summarizes the main results and Section 6 concludes.

\section{Literature Review}

As mentioned before, most of the existing literature on the consequences of conflict on economic activity has focused on cross-country evidence at the aggregate level. The first studies undertaken by authors such as Barro (1991) and Alesina and Perotti (1996) focused on analyzing how political instability affected investment rates and economic growth at national levels. Using cross-country data and different definitions of political instability or conflict, these papers find a negative relationship between these variables and economic activity. Similarly, Collier (1999) estimates that during conflict periods countries' growth is approximately $2.2 \%$ lower than during peaceful times.

In a more recent study, instead of using macro level data at the country level, Gaviria (2002) used information provided by around 100 middle and top managers from the private sector in 29 different countries. Controlling for firms' characteristics as well as for country fixed effects, the author finds that both perceived corruption and crime have a negative and significant effect on investment and employment growth at the firm level. Although the paper investigates both corruption and crime activity, it is worth noting the apparent importance that the former has compared to the latter. First, according to $53 \%$ of the 
interviewed managers, crime is an obstacle for business, while $46 \%$ think corruption is an obstacle. Second, the study's empirical strategy suggests that while corruption lowers sales growth by $30 \%$, crime reduces it by 35\%. Similarly, while corruption appears to have no effect over investment, crime reduces it by $16 \%$.

This cross-country evidence, although suggestive, may suffer from some limitations such as measurement error, omitted variable bias and reverse causality between poverty and conflict if not adequately controlled for. Recent studies have tried to solve these problems using information regarding conflict in a single country in order to study its possible economic impact. Among these studies we find Abadie and Gardeazabal (2003) who evaluate the economic effects that the ETA's terrorist activity has imparted in the Basque Country since its outset in the early seventies. They find that the terrorist activity created a gap of almost ten percentage points between the actual and potential GDP per capita in the region.

Even though there is a great potential for studying the effect of conflict in Colombia, Riascos and Vargas (2011) mention that there are few studies that estimate the impact that both violence and armed conflict have on economic growth. The first studies in the country such as Rubio (1995) estimated the economic costs of conflict through accounting techniques and concluded that the total costs of armed conflict and illegal activities in the country amounted to $15 \%$ of GDP. More recent research has used either time series information for the country (Vargas, 2003 and Cárdenas, 2007), or calibrated theoretical models to Colombian data (Mejia and Posada, 2006). However, all of these papers used aggregate level data such as GDP per-capita or its growth rate.

To the best of our knowledge, the papers that relate conflict variables with firm level data for a single country are Camacho and Rodriguez (2011), Collier and Duponchell (2010), Pshisva and Suarez (2010) and Rettberg (2008). The former study is closely related to this one; it uses the same data set and empirical strategy, but evaluates the general effect of armed conflict on economic activity. The authors find that indeed armed conflict in Colombia increases the probability of firms exiting the market. They find that a one standard deviation increase in the number of guerrilla and paramilitary attacks in a 
municipality increases the probability of plant exit in 5.5 percentage points or 0.28 standard deviations. This effect is stronger for younger manufacturing plants, with a smaller number of workers and low levels of capital.

Collier and Duponchell (2010) uses information from a firm survey conducted by the World Bank in 2006 in Sierra Leone, finding that conflict reduces the number of employees that a firm hires and also the income they receive. Moreover, it appears that the less productive firms are the ones that are affected the most by the conflict. The latter paper carries out a survey to nearly 1,000 firms in Colombia's six largest cities asking their managers how the armed conflict has influenced their operations. Through a descriptive methodology the author concludes that the armed conflict in Colombia affects its firms through channels such as transaction costs, investment, expansion opportunities and firm sales. Pshisva and Suarez (2010) use firm level panel data comprising nearly 10,000 firms for the period 1996-2002 and combine it with information on the number of kidnappings at the state level in Colombia. The authors estimate the effect that kidnaps have on firms' investment decisions under an OLS framework with fixed effects at the firm level. They find that a one-standard deviation increase in firm-targeted kidnappings reduce the investment rate of the average firm from $0.29 \%$ to $-0.28 \%$ of total assets. The authors suggest that the channel through which the effect of kidnaps is transmitted to investment is fear and not demand costs or credit constraints.

Finally Rettberg (2008) through a detailed survey to 113 Colombian firms located in 6 cities find out that the armed conflict in Colombia has negatively affected them. In particular she finds that the conflict increases indirect operational cost. Moreover, the uncertainty generated by the attacks, kidnaps and threats has decreased their investment in research, technology and in hiring more laborers.

Even though previous research has studied the impact of armed conflict on economic activity; only Camacho and Rodriguez (2011) employ data as detailed as the one we use in this paper. As it was previously mentioned, we are able to construct a panel data set at the plant level for all manufacturing firms in the country for a period of ten years. The special and unique characteristics of the data used as well as the estimation strategies makes the 
present paper a contribution to the literature. Moreover, the impact of different characteristics of the armed conflict on firm exit decisions has not been studied before.

\section{Data}

In order to answer our research questions we use Colombian violence and plant level data. Colombia has two detailed and unique data sets that will allow us to study in depth how armed conflict affects entrepreneurial activity.

\subsection{Annual Manufacturing Survey (AMS) 1993-2005:}

The Colombian Annual Manufacturing Survey (AMS) has been conducted by the National Department of Statistics, DANE since 1982. This is an ongoing census of industrial plants with more than 10 employees or a production above 50.000 dollars measured in 2005 prices. The data set allows constructing an unbalanced panel of plants by industry sectors over an extended period of time. We will use annual information by plant on: wages and benefit payments, investments, value added of production and we construct a measure of entry and exit of manufacturing plants.

The information we use in this paper relates to the years 1993-2004. We start our panel in year 1993 because only after this year there is information about location (municipality) of the plant. Moreover, in 1992 the National Department of Statistics changed the coding of the plants and even though one could try to identify each plant of the new survey with past information some observations are lost and the methods are not a hundred percent reliable, as documented by Eslava et al. (2004). With these restrictions in mind, we obtain a nonbalanced panel including 12,714 plants during the period 1993-2004, accounting for 93,188 observations. These plants are located in 296 municipalities out of the 1,120 Colombian municipalities. The observations are well spread within the territory, although of course, most plants are located in big cities such as Bogota, Medellín, Cali, Barranquilla, and Bucaramanga, concentrating almost $65.23 \%$ of the sample. The remaining plants are located in 28 states of the 32 states in Colombia. 
We find a stable distribution of plants across years, with an average of approximately 7,765 plants out of which 452 exit each year. This corresponds to approximately $6 \%$ of all manufacturing plants in Colombia. An important fact in our definition of exit should be noted. The variable exit takes the value of one if we stop observing the plant in a given period and do not observe it again in the sample, and it is zero otherwise. However, as mentioned, the AMS is carried out to all plants with more than ten employees or with a production of above a given range, and hence one could think that a plant that contracts to a smaller scale could be erroneously declared as a plant that left the market. However, we believe this is not the case for three reasons. First, the Statistics Department continues to follow any plant that decreases the number of workers below 10 until this condition of less than 10 employees persists for more than 3 years. This will decrease the error of declaring a plant as if it exited the market when it only temporarily contracted. Second, we only assume the firm exists if we never see the plant in the survey again, so we allow for the possibility of plants that are not followed for a year but then reappear in the sample with the same identification number. Third, it is more likely that an erroneous exit declaration of a plant will occur for those plants with a lower number of workers. Hence, to make sure that we are not erroneously capturing such cases as exits, we carry out robustness checks in the empirical exercises, dropping plants that have less than 10 employees or an annual production of less than 50.000 dollars measured in $2005 .{ }^{6}$

In Table 1 we include descriptive statistics coming from the AMS for our dependent variable, plant exit, and for each of the control variables used in the empirical exercises including wages and benefit payments, investments and value added of production. The table reports information on the sub-sample of plants where there is no missing information. ${ }^{7}$ Wages and investments are $91 \%$ and $67 \%$ of total value added respectively. We also report the descriptive statistics for our estimated measure of productivity.

\footnotetext{
${ }^{6}$ This amounts to drop almost $20 \%$ of the observations.

${ }^{7}$ Differences with the complete sample of firms are not significant for most variables. These statistics are available upon request.
} 
Specifically, we ran a regression of capital and labor on output, and assuming a log linearized Cobb-Douglas production function, we calculate productivity as the Solow residual. This measure has a mean value of zero and a standard deviation of 1.09.

As it was mentioned, the AMS is a census of all manufacturing plants and hence we believe that this data base does not have much bias in terms of firm selection. Two facts give us additional confidence on the accuracy and completeness of the information in this data set. First, Law 79 of October 1993 requires firms to fill out any survey provided by DANE. Second, every year DANE verifies with Confecamaras ${ }^{8}$ to send forms to new firms that qualify into the AMS, firms that will potentially enter into the panel receive pre-surveys to verify their characteristics to enter into the sample.

\subsection{Armed Conflict Data Base 1993-2004:}

The Colombian conflict is one of the longest ongoing domestic confrontations in the world, surpassed in length only by the Israeli-Palestinian and the Indian-Pakistani conflicts. There are three main irregular armed groups acting inside its borders during the period we study. Specifically, there are two guerrilla organizations known as the Revolutionary Armed Forces of Colombia (FARC) and the National Liberation Army (ELN) both of which even though originated in communist ideas in the early sixties, are now also involved in drug producing and trafficking operations. The third group is a rightwing paramilitary group known as the United Self-Defense Forces of Colombia (AUC) with almost twenty five years of existence. Although they demobilized in 2003 and some heads were extradited to the United States, some cells mutated into drug- dealing groups and are still active in the conflict. All three groups besides engaging in direct fight with the national army also perpetrate crimes against the civil population, private assets and public infrastructure. In

\footnotetext{
${ }^{8}$ Confecamaras is the Chamber of Commerce Association where all formal firms are registered and follow certain regulatory standards.
} 
addition to drug production and trafficking ${ }^{9}$, the armed groups finance themselves by extortive kidnapping, although in some cases they kidnap for political motives.

The information on the conflict used in this research comes from a balanced panel at the municipality level from 1988-2004. This data set has been collected along the years through different sources by the CEDE at Universidad de los Andes. ${ }^{10}$ It contains information on all attacks carried out by guerillas and paramilitary groups; as well as deterrence and defensive actions taken by the government during this period of time.

The measure of conflict used in this research will be the total number of attacks carried out by the armed groups against the civil population, its private assets or public infrastructure. Specifically, the total number of attacks will be the sum of explosive terrorist attacks, arsonist terrorist attacks, private property assaults, entity terrorist attacks, political terrorist attacks, route blocking, armed contact, ambushes, harassing, population incursions, other terrorist attacks, land piracy and illegal road blockings. Conflict is widespread all over the country and it varies in intensity across regions.

The average rate of attacks per 100,000 inhabitants in all the municipalities in Colombia is depicted in Figure 1. This measure significantly increased after 1999 and only appears to start to decrease in the year 2004. Such pattern is consistent with the onset of President Uribe's first term when the country was in a deep civil war and both guerrilla and paramilitary groups were active and very strong. In this context, his government established the Democratic Security program, which included a strong military program to fight armed groups and proved to be successful in his first term in office.

\footnotetext{
${ }^{9}$ For a detailed description of the Colombian conflict please refer to Echandía (2006) and Sanchez et al. (2005).

${ }^{10}$ Data was collected from the Vicepresidencia de la Republica, Departamento Nacional de Planeación (DNP), Departamento Administrativo Nacional de Estadistica (DANE), Policía Nacional, Departamento Administrativo de Seguridad (DAS) and Centro de Estudios sobre Desarrollo Económico (CEDE) among others.
} 
As previously mentioned, with the available information we can discriminate who perpetrated any given attack. As presented in Panel D in Table 1 most of the attacks have an unknown perpetrator (an average of 1.83 attacks on average per year), followed by attacks by the two guerilla groups (an average of 0.26 attacks), the paramilitaries (0.04 attacks) and common crime (0.027 attacks). For all of them, except for those attacks with unknown perpetrator, the standard deviation is more than three times its mean value. Panel E of Table 1 presents the average polarization of the conflict in the study period. As previously explained, we define a municipality is polarized if more than $50 \%, 70 \%$ and $90 \%$ of the attacks experienced in a given year are perpetrated by the same armed group. In this manner, we define a polarization index, an index of $50 \%$, indicates that half of the attacks are perpetuated by one group, meaning that there is more than one armed group in the municipality. If the index is $90 \%$, then more than $90 \%$ of the attacks are committed by only one group, implying that there is only one strong group in the region. Almost 92\% of the observations are in regions in which more than $50 \%$ of the attacks are committed by a single group. Moreover, 79\% and 35\% of the observations are in municipalities where 70\% and $90 \%$ of the attacks are perpetrated by a single armed group respectively. This suggests that the Colombian conflict is highly polarized.

As explained, our last question of interest is whether different attacks targets affect in a differential manner firm exit decisions. Panel F of Table 1 separates the total attack rates into two broad groups. The first one encompasses all attacks that target private property while the second one group all terrorist attacks towards the government or the civil population. As can be observed on average there are much more random terrorist attacks than attacks directed to private property. Specifically, while on average each year there are 1.24 terrorist attacks per municipality this number is 0.4 for property attacks.

Finally, this same table presents the average antinarcotics operations as well as the number of drug laboratories dismantled by the army, navy or the national police. On average there are 7.21 antinarcotics operations in each municipality and 1.19 laboratories dismantled per year. As it will be explained in more detail later, these variables are of interest because they will be used as instruments for the total attack rate given that they proxy for deterrence 
actions from the government. As previously mentioned, all Colombian armed groups use drug production and distribution as a major financing source. Hence, higher values of such operations will necessarily be associated with a higher presence of government, police forces and criminal groups in the municipality. This in turn will imply that deterrence actions should be highly correlated with armed conflict measures.

\subsection{Municipal controls:}

After merging the data sets described above, we included additional variables that could help us control for some fixed characteristics at the municipality level different from the level of violence. Among them we include the town surface with an average of 800 square kilometers and an average distance of 60 kilometers to the largest city in the municipality. Additional descriptive statistics of these variables are presented in Table 1. We also include information that varies both at the municipal level and overtime such as: government transfers received by each municipality and GDP levels of the State for each year. Their most relevant statistics are also presented in Table 1.

\section{Estimation Strategy}

There are several channels through which armed conflict could interfere in the productive and commercial activities of the plant. One of the most named channels is that of uncertainty or fear. Fear could naturally reduce investment in both labor and capital, like Pshisva and Suarez (2010) suggest. As documented by Ibañez and Velez (2005) armed conflict could also affect plants' employment if laborers flee the region due to the fear of being killed. In some cases, it could also happen that some civilians may even join the armed groups if they are offered higher wages than those obtained in the legal market. To summarize, the amount of labor supply could vary in different ways: it could depend on the rate of within and between forced migration. Plants located in urban areas of municipalities which have migration from rural to urban areas will see their labor force increase. Plants located in areas where migration happens from rural and urban areas to other municipalities could see a reduction in their labor force. 
Another direct impact of conflict may be related with changes in operational costs. It is plausible to imagine situations in which plants that are located in a violent area would need to increase security if private property is subject to acts of violence. In such cases either additional guard(s) or security systems need to be hired or implemented. Likewise, it could be the case that armed groups charge private firms extortion payments with the threat that if they are not paid, direct terrorism acts could be aimed at the firms. Theoretically, such possibility has been previously analyzed by Konrad and Skaperdas (1998). ${ }^{11}$

Indirect effect for the firms may be numerous too. From the demand side, previous authors such as Verwimp and Bundervoet (2008) have shown that households' consumption growth is reduced under conflict. Hence, it is no surprise that demand for products or services produced by the firms could be reduced and hence probably production and sales would decrease too. Moreover, the reduction in investment, production and sales could in turn reduce the number of laborers plants will want to hire. Finally, another indirect effect that could take place is an increase in credit costs or a reduction in available loans to firms. It is plausible that banks will be willing to lend money to firms located in violent regions only at higher rates so that the higher risks that such loans entail are covered. In extreme cases banks will simply close all the credit lines for such regions.

Through their influence in capital investment, labor hiring opportunities, changes in costs of production and effective customers' sales armed conflict have a significant effect on a plant's exit decision. Camacho and Rodriguez (2012) formalize these ideas using a simple model of firms' decisions under a Cobb-Douglas production function. Based on it is simple to obtain that the reduced form of firm $i$ exit decision in time $t$ will be given by:

$$
\operatorname{exit}_{i, t}=f\left(V A_{i, t}, w L_{i, t}, r I_{i, t}, v i o_{m, t}\right)
$$

\footnotetext{
${ }^{11}$ Specifically, for Colombia a recent example of such bribes is that supposedly made to Blockbuster by a guerrilla group. The multinational company refused to pay them the demanded bribe and on January $27^{\text {th }} 2009$ a bomb in one of its stores was exploded in Bogota. (More details in El Tiempo, January 28th 2009 "Autoridades atribuyen a extorsión atentado que dejó dos muertos en Bogotá")
} 
Where $\mathrm{VA}_{\mathrm{i}, \mathrm{t}}$ represents the value added of the firms production in year $t, \mathrm{wL}_{\mathrm{i}, \mathrm{t}}$ is the firms nominal wage paid to laborers and $\mathrm{rI}_{\mathrm{i}, \mathrm{t}}$ represents nominal investment in year $t$. Finally, vio $_{\mathrm{m}, \mathrm{t}}$ represents our variable of interest related to the conflict in municipality $m$ where the plant is located in year $t$. This is the basic structure that all the estimations presented in this paper will have; the main difference across them is the specific representation that the vio $\mathrm{t}_{\mathrm{t}}$ variable takes. Specifically, we will have four different specifications depending on the question of interest.

In the first specification we will use the same variable as in Camacho and Rodriguez (2012) in which vio represents the total number of attacks in a given municipality in year $t$ and will serve as our baseline model. In a second exercise vio ${ }_{t}$ will represent the total number of attacks perpetrated by the five possible different groups in the municipality that could perpetrate the attacks, namely FARC, ELN, AUC, common delinquency and unknown. The third exercise has as variable of interest the effect of polarization of the conflict on firms' decisions. Hence vio ${ }_{\mathrm{t}}$ represents a dummy variable equal to one if a given percentage of the attacks experienced in a given municipality in year $t$ were perpetrated by the same armed group. These percentages will be 50, 70 and 90\% respectively. Finally in the fourth

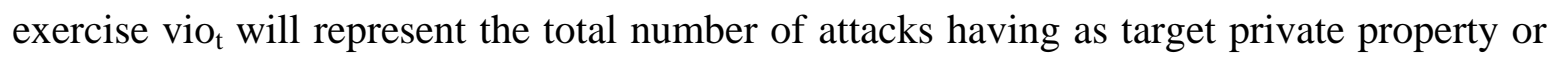
random terrorist attacks.

The use of the unique data described in Section 3 will allow us to use panel data techniques to answer our question of interest. As it is well know, this technique is highly valuable given that, among other things, it allows the researcher to control for all the constant unobservables that could affect the outcomes of interest. For our specific case, panel data techniques could for instance control for the managerial abilities or political affiliation of the owners of plants that will indeed influence the decisions taken and hence the results attained by them. This will improve the quality of our estimations.

Specifically, the simplest specification that we estimate is given by:

$$
y_{i, m, t}=\beta_{0}+\beta_{1} v_{m, t}+\beta_{2} d_{i, m, t}+\beta_{3} x_{m, t}+\beta_{4} f_{i, m, t}+\gamma_{t}+\delta_{i}+u_{i, m, t}
$$


Where $y_{i, m, t}$ represents the exit decisions for plant $i$ located in municipality $m$ and at time $t$. The variable $v_{m, t}$ represents the violence or armed conflict that took place in municipality $m$ and at time $t$ as explained above. We include $d_{i, m, t}$ as a variable that captures duration of the plant in the panel. The vector $x_{m, t}$ represents constant and time varying municipal characteristics such as the municipality area, the distance to the main city in the municipality, the GDP of the state, and transferences from the Central Government. The vector $f_{i, m, t}$ represents plant characteristics changing over time, such as nominal investment, total nominal wages paid and added value all of which come from our theoretical model. Finally, $\gamma_{\mathrm{t}}$ and $\delta_{\mathrm{i}}$ represent year and plant fixed effects respectively and $u_{i, m, t}$ is an error term assumed to be orthogonal to plant exit.

Under specification (8), $\beta_{1}$ is the coefficient of interest which will give an estimate of the effect that the different characteristics of armed conflict has on plant exit. However, one must be cautious when interpreting this result given that reverse causality and endogeneity could be biasing our estimation of $\beta_{1}$.

Several studies have previously shown that economic activity is an important determinant on the onset and duration of civil conflict. Among some of these studies we find Collier and Hoeffler (2002), Fearon and Laitin (2003) and Miguel et al. (2004) all of which, using cross-country information, have found that levels and growth rates of GDP have a negative effect on armed conflict measures. There are many channels through which such reverse causality could emerge. For instance, lower economic activity may be associated with fewer labor opportunities or lower wages for young men. Under such scenarios it would be easier for armed groups to recruit new members and an escalation of the conflict could take place. Another possibility is that plant's location is endogenous to levels of violence. A plant will take into account violence conditions when deciding whether to open business or not. In this manner, one could expect that the strongest or more able plants to face conflict will open and stay in the market.

For the reasons previously explained we must take into account the possibility of endogeneity in our conflict measure $v_{m, t}$. Studies such as Collier and Hoeffer (2002) and Fearon 
and Laitin (2003) have previously used lagged independent variables to solve reverse causality problems between economic activity and armed conflict. However, the problem with this approach is that if there is any inertia in the armed conflict measure or in economic activity lagged measures of the former, this methodology will not necessarily solve the endogeneity problem.

For this reason we use an instrumental variables approach in which we explain the armed conflict present in municipality $m$ at time $t$ with lagged laboratories dismantle $z_{1 m, t-1}$ and antinarcotics operations $Z_{2 m, t-1}$ in municipality $m$ at time $t-1$. Our first stage will be given by the following equation:

$$
v_{m, t}=\partial_{0}+\partial_{1} z_{1 m, t-1}+\partial_{1} z_{2 m, t-1}+\beta_{2} d_{i, m, t}+\beta_{3} x_{m, t}+\beta_{4} f_{i, m, t}+\gamma_{t}+\delta_{i}+u_{i, m, t}(9)
$$

Where violence in municipality $m$, at time $t$ is explained by all the exogenous regressors. We used these two instruments for two main reasons. First, the dismantle of laboratories and antinarcotics operations rate in municipality $m$ at time $t-1$ should be highly correlated with armed conflict given that it serves as a measure of both the presence and effectiveness of the Government to counteract criminal activity in the region. That is, we would expect to find a negative association between this government's deterrence measure and armed conflict intensity, as will be shown in our first stage regression. However, note that both variables are related to drug production which is known to be the main financing source of the Colombian armed groups. Hence, if these groups try to protect such laboratories or production sites through armed attacks, it could also be the case that a positive relationship between armed conflict and such deterrence measures could emerge. The second reason behind our choice of instruments is that we believe on their exogeneity. It is hard to state that production and commercial decisions of managers today will be based on these specific central government deterrence decisions which are normally secret operations that occur in environments not easily detected by the civil population.

It should be noted that the paper by Angrist and Kugler (2008) gives further support for our instruments. In their study, the authors find that indeed an exogenous upsurge in coca 
cultivation increased violence in the regions where it was produced. They explain that a possible mechanism through which this takes place is by the resources that drug production gives to Colombian armed groups. Furthermore, the authors also find little evidence to suggest that increased coca production benefited economic activity in the producing regions. Although the income of some rural dwellers increased, they argue that regional economies are not closely related to the drug business and that most of the resources from this activity go directly to the insurgent hands. Given that manufacturing is clearly a more urban and legal activity it is even harder to find channels through which antinarcotics deterrence actions should influence plant exit decisions.

The instrumental variable approach is our preferred estimation strategy not only because it addresses the endogeneity problem directly but also because it could reduce any possible bias due to measurement errors or omitted variables. Of course both requirements for a good set of instruments will be tested empirically. That is we will need to prove that both deterrence measures are strongly related with our variable of interest and that they are exogenous to plants' exit decisions.

\section{Results}

\section{General armed conflict and firms' exit decisions}

Different specifications of equation 8 are presented in Table 2 as we gradually include controls into the regression. ${ }^{12}$ The first six columns are the OLS estimates related with contemporaneous measures of armed conflict while the last six relate with IV estimates. Column one only includes as controls the duration variable as well as plant and year fixed effects; the second column adds the municipal controls described above; and the last specifications include all the set of controls by gradually adding plants' specific characteristics that arise from the model described in Camacho and Rodriguez (2012). Even

\footnotetext{
${ }^{12}$ We decided to use data only from those plants that have information from all our control variables. That leaves us with 35,000 observations to be able to compare the coefficient of interest across specifications. Nonetheless, results are maintained using the complete sample in specifications that do not include all control variables. All of them are available upon request.
} 
though we are controlling for fixed effects at the plant level the inclusion of constant municipality characteristics is possible given that out of the 12,714 plants, 862 of them changed location during the period under study.

As shown in the OLS specifications presented in Table 2, the intensity of conflict appears to have no effect over plant exit. All coefficients of interest in these regressions are actually zero. However, as described above, these results need to be interpreted with caution given the possible reverse causality that can exist between economic activity and armed conflict. The last six columns of Table 2 try to address the problem of endogeneity using an instrumental variable approach. Specifically, we evaluate the effect that armed conflict measures, instrumented by lagged laboratories dismantle and antinarcotics operations at the municipality level have on entrepreneurial activities. This is our preferred strategy not only because it directly addresses the endogeneity problems but also because any bias due to omitted variables or measurement errors will also decrease.

Our instruments, laboratories dismantle and antinarcotics operations of the previous period influence in a significant manner the level of armed conflict in the municipality independently of the controls used. Moreover, the F-test, presented in the second panel from Table 2, shows that under these specifications we will not suffer from any weak instrument problem. Additional to the relevance of the instruments, we also need to address the exogeneity of our chosen instruments and the endogeneity of the armed conflict measure in the exit specification. Both of these questions are answered in the second panel of Table 2 which presents the results for the Sargan and endogeneity test of the instruments and armed conflict respectively. In the former test the null hypothesis is that, assuming that one of the instruments is exogenous, the second one is also exogenous. None of the Sargan tests from different specifications in Table 2 reject the null hypothesis under a reasonable significance level. The null hypothesis of the endogeneity test is that the armed conflict measure is an exogenous variable in the empirical specification and hence no IV procedure should be needed. In this case however, we reject such hypothesis in all specifications with a one percent confidence level implying that an IV estimation is indeed needed. 
The results of the second stage for the exit decision of plants are presented in the last six columns of Table 2. Under the two stage procedure we can observe that armed conflict has a positive and significant effect on plant exit. Column one shows that after controlling only for plant fixed effects, year effects and duration of the plants, the hazard rate that of a plant exiting the market increases in 6.1 or 5.5 percentage points with a one standard deviation increase in the total attack rate or evaluated at the mean respectively. Alternatively, this amounts to a change in 0.3 and 0.28 standard deviations respectively, which is clearly not a small effect. Of course, it is worth noting that this coefficient may be biased given that there could be characteristics at the municipality level that are constant or vary over time and may be correlated both with plant exit decisions and with armed conflict. To reduce these possible sources of biases column two includes municipality characteristics that are constant as well as some that vary over time. As it can be observed, there was a significant bias in the coefficient given that it reduces in nearly 26\%. However, it remains economically important and highly significant. Specifically, it is estimated that an increase in one standard deviation of our armed conflict measure increases the probability that a plant will exit the market by 0.22 standard deviations.

Given that we control for year and plant fixed effects, and for municipality characteristics that proxy for the potential size of the markets, as well as economic activity and poverty levels, we can say that the effect observed in column two corresponds to the impact of armed conflict on plant exit decision. By adding the plant's control variables we can disentangle some of the channels thorough which this effect may take place. Under the last specification that includes all control variables we find that an increase in one standard deviation of armed conflict increases the probability of plant exit by 0.28 standard deviations.

\section{Specific armed conflict characteristics and firms' exit decisions}

Results presented in Table 2 describe the effect of armed conflict on firm exit decisions regardless of its characteristics. However, the interest of this paper is to understand how different characteristics of armed conflict decisions may differentially affect firm exit. 
The first characteristic we take into account is the armed group that perpetrates each attack. As it was previously mentioned, during the period of 1993 and 2005, there were three main actors in the Colombian armed conflict: two left wing guerilla groups (FARC and ELN) and a right-wing paramilitary group (AUC). According to the different nature of these groups, it could be possible to expect that the objectives (among the conflict actors, the businesses sector and civil agents) and types of terrorist attacks perpetrated vary among the three groups. In a similar manner, it is possible that the civil society and the entrepreneurs see and relate to the three groups in different ways. As a result of this, the firm's exit decisions could vary according to which actor of the conflict commits the attacks in a given municipality.

The data availability allows us to observe these differences, analyzing as variable of interest the number of attacks committed by each of the three groups: AUC, FARC, ELN, and a fourth and fifth categories, common crime and unknown actor. Following the described estimation strategy Table 3 presents the results under OLS and the IV methodology which controls for the endogeneity problems. In each model we evaluate the effect of the number of attacks by 100,000 inhabitants perpetrated by each of the mentioned armed groups on firm exit decisions. As in Table 2, we estimate the model gradually including the different municipality and firm level controls, but in this case we only present the most complete estimation. $^{13}$

The results are quite interesting and show that there are heterogeneous effects on firm exit decisions according to which actor of the conflict perpetrates the attack. As it is observed on Table 3, the attacks committed by the AUC do not have a significant effect. Moreover they do not appear to be endogenous and hence no IV methodology is needed. This might be an expected result given that this group has been historically associated with the richest population (landowners and entrepreneurs) and hence do not traditionally attack them. In fact, they were originally created to protect wealthy families from guerrilla groups.

\footnotetext{
${ }^{13}$ All results are similar and are available upon request.
} 
On the contrary, attacks conducted by the two guerilla groups or common delinquency do affect firm exit significantly. Specifically, we see that an increase in a one standard deviation in the attacks rate by FARC increases by standard deviations the probability of plant exit. Nonetheless this result needs to be taken with caution. First the coefficient is significant at the 11 percent significance level. More importantly, the F test suggests that the instruments may not be the most appropriate ones and that we may be suffering from a weak instrument problem. For the other three groups we do not have this problem given that the instruments are all highly relevant, assuming one is exogenous the other one is exogenous too and the variable of interest was indeed endogenous. For ELN attacks we see that an increase in one standard deviation increases firm exit probability in 0.36 standard deviations. Similarly, an increase in one standard deviation in the attacks perpetrated by common criminals or unknown groups increase the probability of firm exit by 0.22 and 0.23 standard deviations respectively.

Table 4 presents the results associated with the levels of polarization of the conflict for municipalities with an index of polarization of higher than 50\%, $70 \%$ and $90 \%$ respectively. For each level of polarization three models are presented. The first one presents the result for OLS with all control variables, model 2 presents the IV results with only plant and year fixed effects, while model 3 presents the IV results incorporating all control variables. For this last specification it is important to notice that the deterrence instruments chosen are appropriate in the sense that the $\mathrm{F}$ test is sufficiently high so there is no evidence of weak instruments being present. Similarly the Sargan test is passed and the polarization variables are indeed endogenous.

It is interesting to note that there appears an inverse relationship between the polarization index and the probability of firm exit. Using all municipalities where 50\% of armed attacks are perpetrated by one single armed group we find that an increase in one standard deviation in the number of attacks increases the probability of firm exit in 0.3 standard 
deviations. This number changes to 0.23 and 0.09 when the polarization index is $70 \%$ and $90 \%$ respectively.

The last source of heterogeneous effects that we evaluate is whether different types of attacks affect the firm's exit decision in a specific manner. We analyze two types of attacks, attacks on property and regular terrorist attacks. One could expect the effect of attacks on property to be more significant, taking into account that they are directed towards capital and infrastructure, while terrorist attacks are aimed at alarming civil society as a whole. The results are shown in Table 5, where, as before, we include estimations following the approach of OLS, instrumental variables and gradually including regression controls. As in the previous regressions the instruments prove to be relevant and the variable of interest is endogenous. In this case however it should be noted that we reject the null hypothesis that if one of the instruments is exogenous the other one also is. Having this caveat in mind it can be seen, that the effects of property-aimed attacks are greater than terrorist attacks. Specifically, an increase in one standard deviation on the rate of attacks on property increases the probability of firm exit in 0.33 standard deviations. If the attack is a terrorist attack as defined in the data section the increase in the hazard of exit is of .024 standard deviations.

\section{Conclusions}

Using a combination of two unique data sets this paper estimates the effect that different characteristics of the armed conflict have on exit decisions of manufacturing plants in Colombia. Having one of the longest ongoing civil conflicts in the world, Colombia is a good country to analyze this subject. Under an instrumental variable methodology, which controls for possible endogeneity problem, we find that armed conflict has a significant effect in the exit decisions of the plants. Specifically, an increase in one standard deviation in the number of guerrilla and paramilitary attacks in a municipality increases the probability of plant exit in 5.5 percentage points or 0.28 standard deviations. However, it is important to take into account that our results cannot be generalized for all plants in the 
country, but only for those in with more than 10 employees and in the manufacturing sector.

Regarding other interesting heterogeneous effects, we find that the effect of the armed conflict on firm's exit decisions is different when the attack is committed by a guerrilla groups compared to the right wing paramilitary. Also, the effects are stronger in municipalities where the index of polarization is lower, meaning that there is more than one strong armed group. Finally, we find that the effects on firm exit are higher when the perpetuated attacks are directed towards property rather than regular terrorist attacks aimed at alarming the civil society.

The present research is a first step to fill an important gap in the conflict and economy literature. Contrary to previous studies that are based on cross-country information or aggregate variables such as GDP growth, we are able to understand which and how plants' decisions are influenced by an armed conflict. These first results contribute to the understanding of the possible direct channels through which conflict influences economic activity. The results of this paper can also enrich governments' and NGOs' knowledge in order to design suitable policies that aim to counteract the negative consequences of war and reduce its negative impact on development. The results suggest that special attention should be given to manufacturing plants in area with prevalent common crime, strong guerilla presence, and where there is less polarization of conflict.

This is a very young research question and hence further research is needed to understand the effect of conflict over other important entrepreneurial decisions and the specific channels that may drive the results here found. Among them we should mention the effect on capital stock and investment decisions, the number of employees hired at the plants, the proportion of male and production laborers, the real wages paid by the plants and the level of productivity. 


\section{References}

Abadie, Alberto and Javier Gardeazabal. 2003. The economic costs of conflict: a case study of the Basque country. American Economic Review 93 (1): 133-32.

Alesina, Alberto and Roberto Perotti. 1996. Income distribution, political instability, and investment. European Economic Review 40 (6): 1203-28.

Alvarez, Roberto and Holger Görg 2009. Multinationals and plant exit: evidence from Chile. International Review of Economics \& Finance 18 (1): 45-51.

Angrist, Joshua and Adriana D. Kugler. 2008. Rural windfall or a new resource curse? Coca, income, and civil conflict in Colombia. The Review of Economics and Statistics 90 (2): 191-215.

Audretsch, David B. and Talat Mahmood. 1995. New firm survival: new results using a hazard function. The Review of Economics and Statistics 77 (1): 97-103.

Barro, Robert. 1991. Economic growth in a cross-section of countries. Quarterly Journal of Economics 106: 404-44.

Bernard, Andrew and Bradford Jensen. 2007. Firm structure, multinationals, and manufacturing plant deaths. The Review of Economics and Statistics 89 (2): 193-204.

Blattman, Chris and Edward Miguel. 2010. Civil War. Journal of Economic Literature, 48(1), 3-57

Cárdenas, Mauricio. 2007. Economic growth in Colombia: a reversal of 'fortune'? Ensayos Sobre Política Económica 25 (53): 220-259.

Collier, Paul. 1999. On the economic consequences of civil war. Oxford Economic Papers 50 (4): 563-73.

Collier, Paul and Anke Hoeffler. 2002. On the incidence of civil war in Africa. Journal of Conflict Resolution 46 (1): 13-28

Collier, Paul and Marguerite Duponchel. 2010. The Economic Legacy of Civil War: Firm Level Evidence from Sierra Leone. WIDER Working Paper, 90. 
Fearon, James D. and David D. Laitin. 2003. Ethnicity, insurgency, and civil war. American Political Science Review 97 (1): 75-90.

Gaviria, Alejandro. 2002. Assessing the effects of corruption and crime on firm performance: evidence from Latin America. Emerging Markets Review 3 (3): 245-68.

Harbom, Lotta and Peter Wallensteen. 2007. Armed conflict, 1989-2006. Journal of Peace Research 44 (5): 623-34.

Iyigun, Murat and Dani Rodrik. 2006. On the efficiency of Reforms: Political Tinkering, Insitutional Change and Entrepreneurship. Institutions, Development, and EconomicGrowth. Vol 1. MIT Press.

Konrad, Kai A. and Stergios Skarpedas. Extortion. 1998. Economica, 65, (260): 461-477.

Mejia, Daniel and Carlos Posada. 2006. Capital Destruction, Optimal Defense and Economic Growth. Journal of World Economic Review, 1 (1): 33-55.

Miguel, Edward, Shanker Statyanath, and Ernest Sergenti. 2004. Economic shocks and civil conflict: an instrumental variables approach. Journal of Political Economy 112 (4): 725-53.

Munshi, Kaivan. 2007. From Farming to International Business: The Social Auspices of Entrepreneurship in a Growing Economy. National Bureau of Economic Research Working Paper 13065.

Pshisva, Rony and Gustavo Suarez. 2010. Capital Crimes: Kidnappings and Corporate Investment in Colombia. In The Economics of Crime: Latin America and International Perspectives. University of Chicago Press

Rettberg, Angelika. 2008. Explorando el Dividendo de la Paz: Impactos del Conflicto Armado en el sector privado colombiano, resultados de una encuesta nacional. CESO, Ediciones Uniandes.

Riascos, Alvaro and Juan F. Vargas. 2011. Violence and growth in Colombia: a brief review of the literature. Economics of Peace and Security Journal 6(2): 15-20.

Rubio, Mauricio. 1995. Crimen y Crecimiento en Colombia. Coyuntura Económica. 25(1): 101-127.

Sanchez, F., Solimano, A. and Formisano, M., 2005. Conflict, Violence and Crime in Colombia. Understanding Civil Wars, Volume. 2, The World Bank. 
Vargas, Juan Fernando. 2003. Conflicto Interno y Crecimiento Económico en Colombia. Tesis PEG. Bogotá: Universidad de los Andes.

Verwimp, Phillip and Tom Bundervoet. 2008. Consumption growth, household splits and civil war. Research Working Paper 9. Brighton: MICROCON. 
Figure 1: Total Attack Rate over Time-All Municipalities

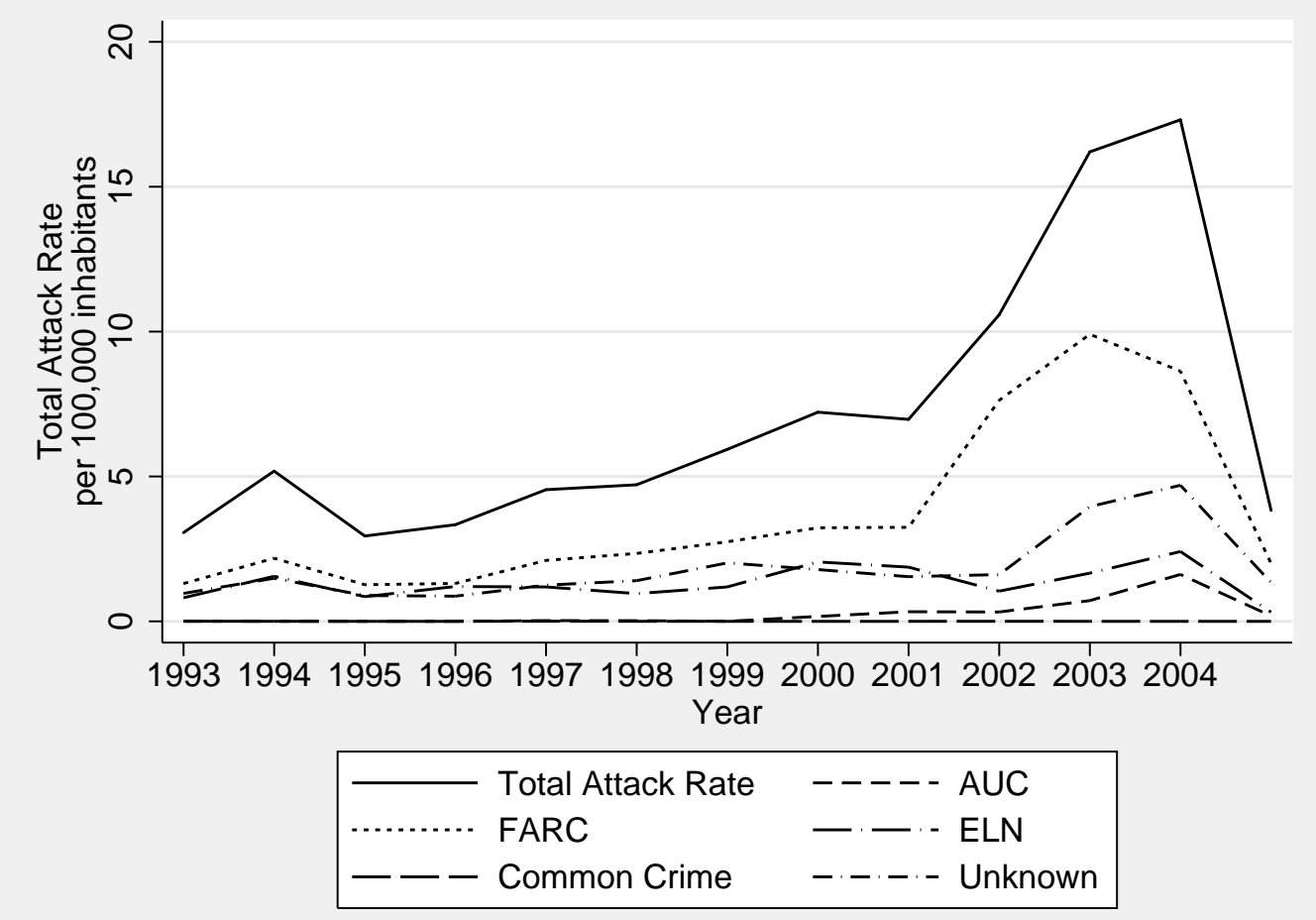




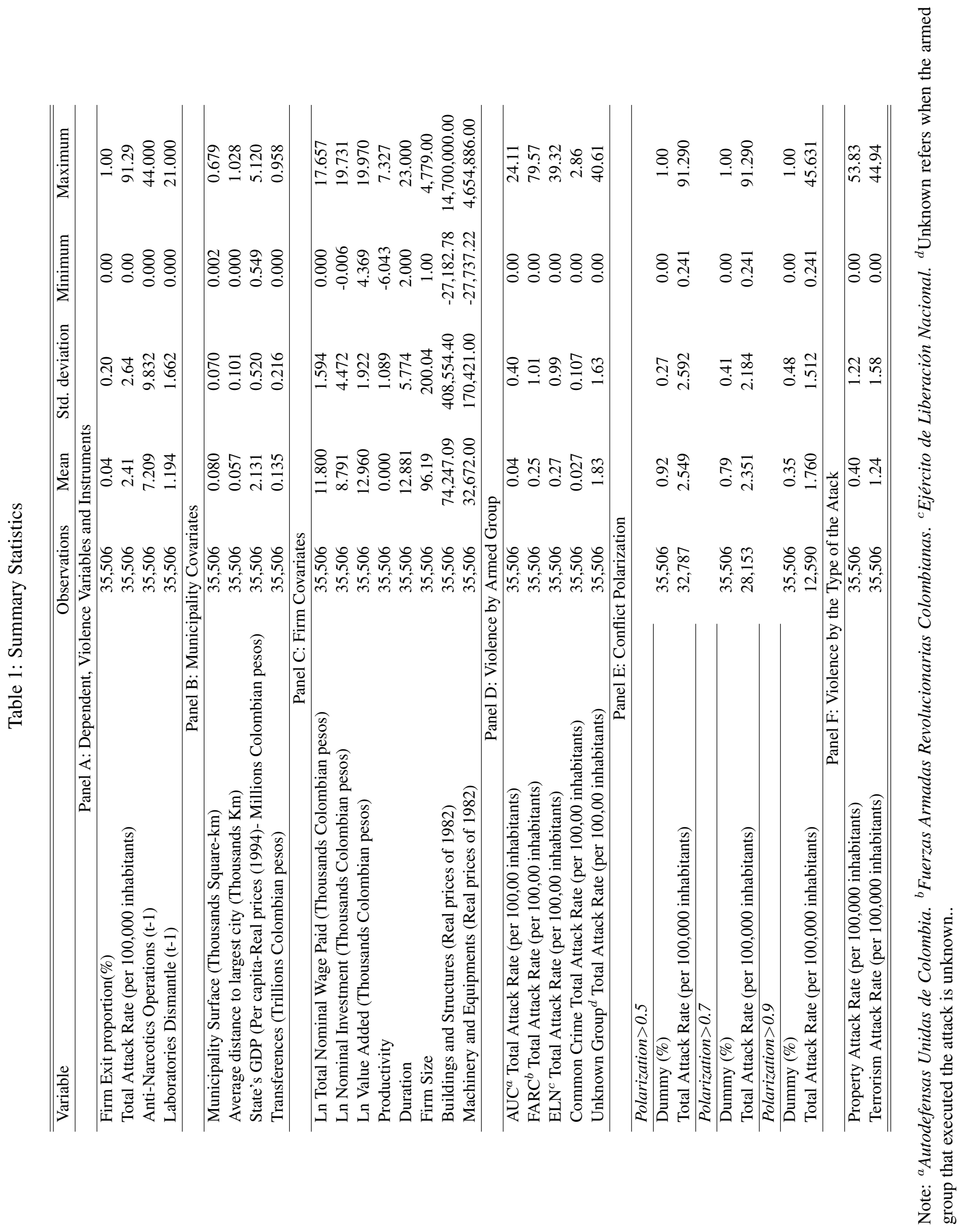




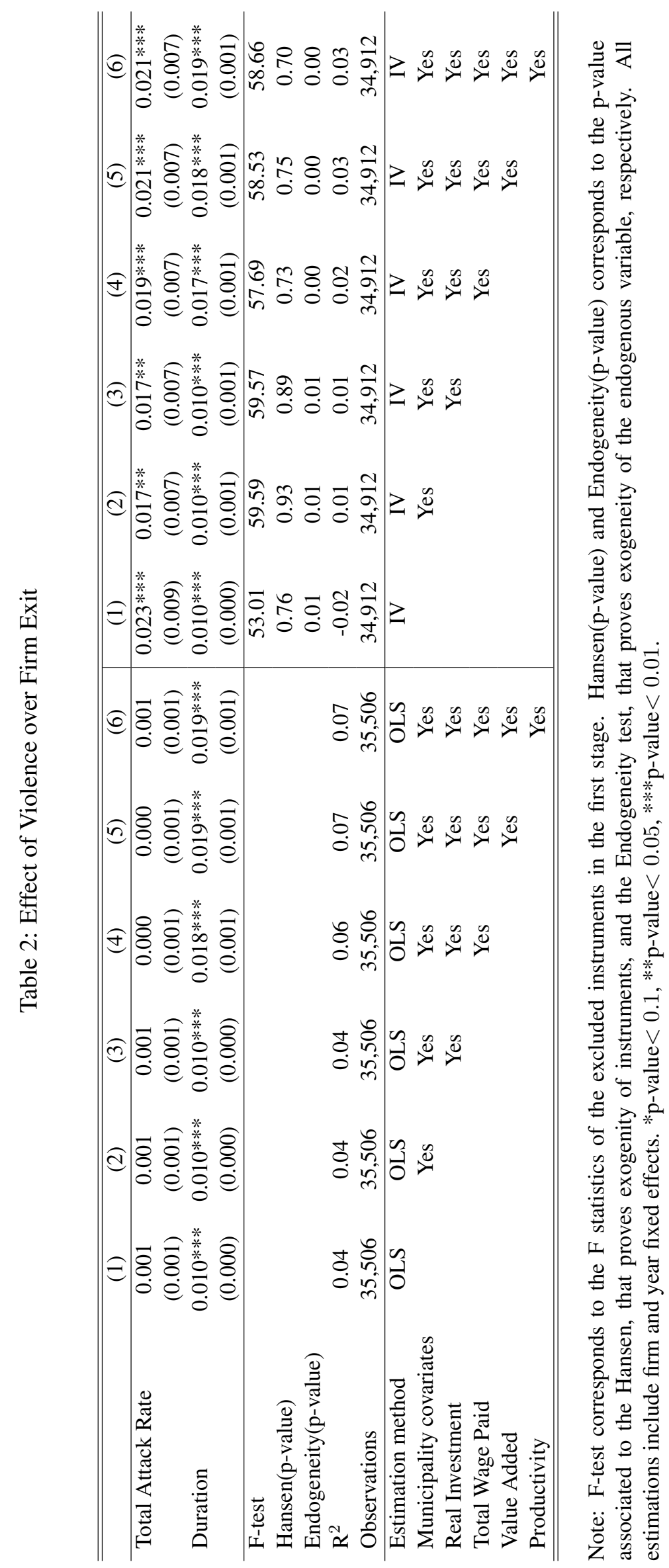




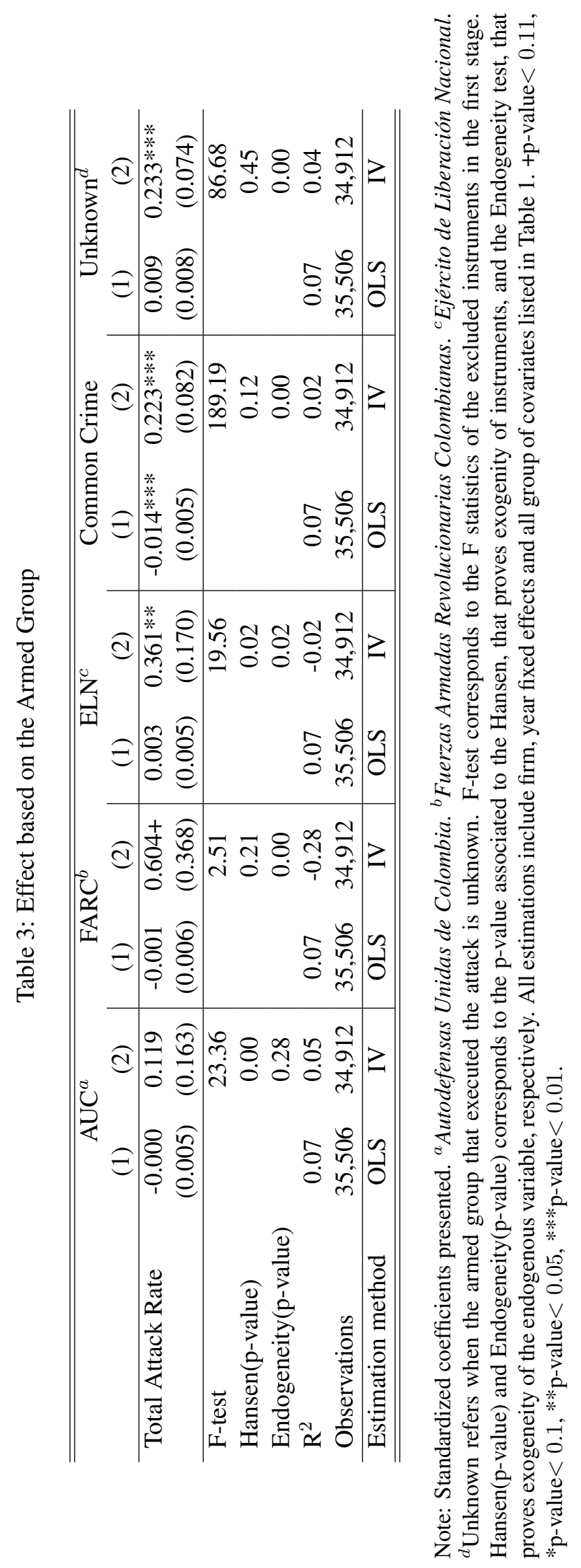




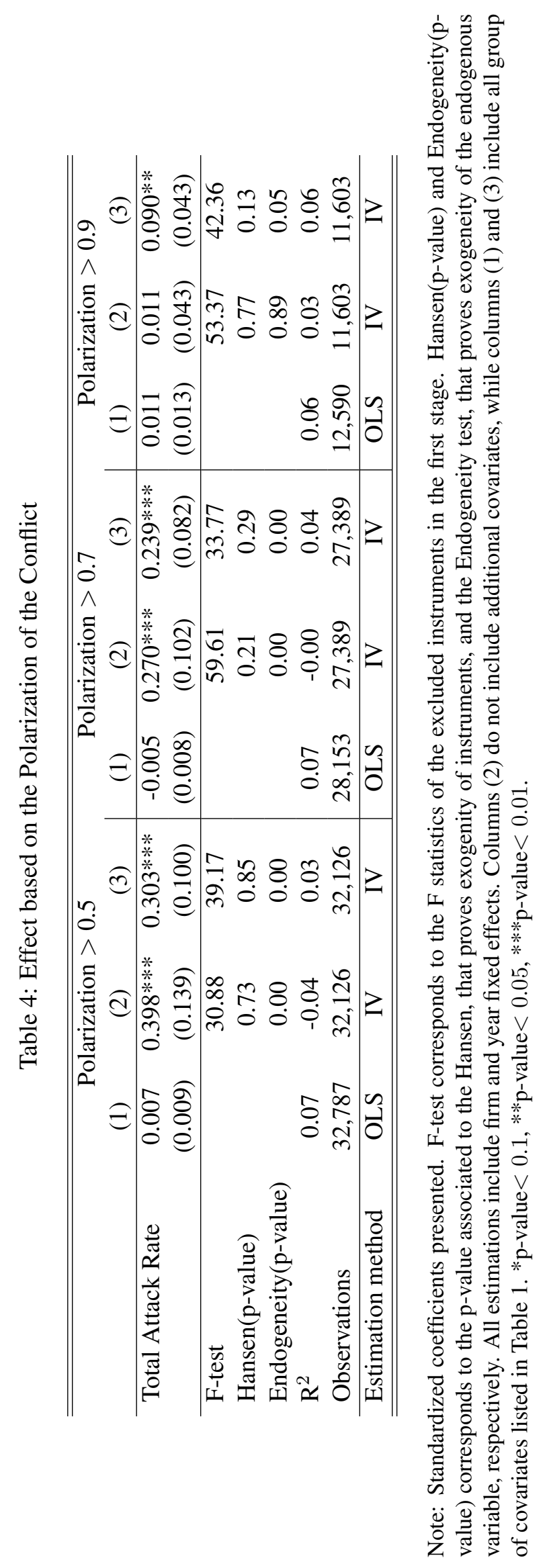


Table 5: Effect based on Type of Attack

\begin{tabular}{lccc|ccc}
\hline \hline & \multicolumn{3}{c}{ Property } & \multicolumn{3}{c}{ Terrorism } \\
& $(1)$ & $(2)$ & $(3)$ & $(1)$ & $(2)$ & $(3)$ \\
\hline Total Attack Rate & 0.008 & $0.193^{* *}$ & $0.335^{* * *}$ & 0.006 & 0.061 & $0.240^{* *}$ \\
& $(0.008)$ & $(0.096)$ & $(0.130)$ & $(0.007)$ & $(0.118)$ & $(0.106)$ \\
\hline F-test & & 59.66 & 30.53 & & 53.27 & 62.10 \\
Hansen(p-value) & & 0.10 & 0.09 & & 0.01 & 0.03 \\
Endogeneity(p-value) & & 0.04 & 0.01 & & 0.63 & 0.02 \\
$\mathrm{R}^{2}$ & 0.07 & -0.00 & -0.04 & 0.07 & 0.03 & 0.04 \\
Observations & 35,506 & 34,912 & 34,912 & 35,506 & 34,912 & 34,912 \\
\hline Estimation method & OLS & IV & IV & OLS & IV & IV \\
\hline \hline
\end{tabular}

Note: Standardized coefficients presented. F-test corresponds to the F statistics of the excluded instruments in the first stage. Hansen(p-value) and Endogeneity(p-value) corresponds to the p-value associated to the Hansen, that proves exogenity of instruments, and the Endogeneity test, that proves exogeneity of the endogenous variable, respectively. All estimations include firm and year fixed effects. Columns (2) do not include additional covariates, while columns (1) and (3) include all group of covariates listed in Table $1 .{ }^{*}$-value $<0.1, * *$ p-value $<0.05, * *$ p-value $<0.01$. 